\title{
The assessment of the impact of natural and anthropogenic factors on the current stress- strain state of rock massif of burst-hazardous ore deposits in the East of Russia
}

\author{
Igor Rasskazov ${ }^{1 *}$, Boris Saksin ${ }^{1}$, Vitaly Usikov $^{1}$ and Alexander Sidlyar ${ }^{1}$ \\ ${ }^{1}$ Mining Institute of Far eastern branch of Russian Academy of Sciences, Khabarovsk, Russia.
}

\begin{abstract}
This paper does a case study of endogenous deposits located in the zone of influence of convergent (converging, colliding) boundaries of tectonic plates in the zone of the continent-ocean transition, where there is increased present seismic and geodynamic activity, covers the issues of the ratio of natural and anthropogenic components of the stress-strain state (SSS) in rock massifs. It has been shown that, despite the confinement of the studied deposits to a single rock structure, as well as the proximity of their common neotectonic position, the SSS of the rock massifs containing them varies significantly. Based on a comprehensive analysis of geological and geophysical data with the use of space data about the Earth (GRACE mission data for calculation of stress fields and radar images of the Earth's surface), the kinematics of the process of modern deformation of the upper part of the Earth's crust within the studied area is specified. It is established that the peculiarity of the region is the pronounced contribution of the natural component to the general present SSS of rock massifs of impactthreatening deposits. On a real example, the possibility of a predictive assessment of SSS has been shown, which is important at the stages of designing and conducting underground mining operations in severe mining-geological and burst -hazardous conditions. Keywords: Rock bursts, mine seismicity, geodynamics, remote sensing of the Earth, stressstrain state, tectonic structure, forecast
\end{abstract}

\section{Introduction}

During underground development of subsoil in severe mining and geological conditions and at great depths, one of the most difficult and topical problems is preventing rock bursts and other dangerous geodynamic phenomena. The difficulty of solving this problem is due to the complexity of the geological structure of the deposits, the high heterogeneity of the properties and the state of the rock masses composing them, which is further strengthened as a result of mining rocks $[1,2]$. At a certain stage of mining, the risk of manifestation of such formidable phenomena as mining-tectonic impacts and man-made earthquakes with catastrophic consequences increases. A sign of increasing geodynamic risk is mine

\footnotetext{
* Corresponding author: rasskazov@igd.khv.ru
} 
seismicity, which reflects the process of redistribution of stresses in a rock massif and its structural reorganization under the influence of intensive mining [3-6].

In the conditions of dangerous and burst-prone deposits of Far Eastern region, it is established [1] that the stress-strain state (SSS) of rock massifs is significantly influenced by the heterogeneity of the regional natural background, on which the stress field formed in the natural-technical system is superimposed. Accounting for the SSS of the rock massif, especially at the stage of mining design, ensures effective and safe mining of deposits.

All this requires further improvement of methods and tools for studying the geological environment under conditions of intense man-made impact, obtaining and rethinking new experimental data obtained in regions with different geodynamic regimes.

\section{Analysis of the geodynamic position of the burst-hazardous deposits of the East of Russia}

In the East of Russia, a significant number of ore deposits (tin, tungsten, polymetals, noble metals, etc.) are concentrated within the relatively young Pacific orogenic belt, which position is controlled by the zone of interaction of the Pacific and Asian tectonic plates and the global East Asian system of shifts, having north-eastern orientation [7]. According to the regionalization scheme for the territory of the USSR in terms of the absolute value of the maximum tangential stresses in the Earth's crust (Gzovskiy, 1975), the area under investigation is characterized by a sufficiently high level of stress equal to $70 \pm 35 \mathrm{MPa}$, which is inherent in active modern orogenic regions. Long-term geodynamic studies on the ore deposits of the region have revealed the specificity of the manifestation of rock pressure in the described territory, which is proposed to be attributed to a particular type of EdgeAsian type of model regions [1].

Territories of this type are located in the zone of influence of convergent (converging, colliding) boundaries of tectonic plates, where as a result of long-term and still continuing interaction of plates, a shift-magmatic regime of formation of the structure of ore fields is created and increased modern seismic and geodynamic activity is observed. As a result, in the upper horizons of the Earth's crust, as a rule, anomalous deformation is established here, due to the fact that excess stresses acquire a non-gravitational nature, and the main interactions and structural-material transformations of the geological environment are carried out due to mechanical energy. For such conditions, the effect of a very uneven stress state of sections of rock massifs and an increased activity of neotectonic processes are characteristic. This cannot but leave an imprint on the local geodynamic system, and, consequently, on the character of the dynamic manifestations of rock pressure. This is confirmed by the results of full-scale studies in the conditions of burst-hazardous deposits in the East of Russia, in the massifs of which horizontal compressive stresses (due to the action of tectonic forces) are exceeded over vertical (gravitational), which is largely determined by their geodynamic position within the tectonically active Amur plate (Table 1).

The authors will examine in more detail the Nikolaevskoye, Yuzhnoye and Vostok-2 deposits located within the Sikhote-Alinsky segment of the Pacific orogenic belt in the area of its articulation with the Central Asian orogenic belt. They are confined to the zone of active interaction between the Amur and Okhotsk tectonic plates of the next hierarchical level. These are postmagmatic deposits attributed to vein, stockwork and skarn types. They consist of a composition of predominantly steeply dipping ore bodies. Despite the proximity of their common neotectonic position, the nature and parameters of the stress field of these deposits are significantly different, and the burst hazard manifests itself at different depths. 
Table 1. Parameters of stress fields in rock massifs of some bump-hazardous deposits of Far Eastern region

\begin{tabular}{|l|c|c|c|}
\hline \multicolumn{1}{|c|}{ Deposit } & Digging depth, $\mathrm{m}$ & Maximal stress, MPa & $\begin{array}{c}\text { Ratios of primary stresses } \\
\left(\sigma_{l}: \sigma_{2}: \sigma_{3}\right)\end{array}$ \\
\hline Nikolaevskoye & 860 & $70-150$ & $2.5: 1.5: 1$ \\
\hline Yuzhnoye & 500 & 95 & $1.8: 1: 1$ \\
\hline Vostok-2 & 500 & $50-70$ & $2.5: 1.3: 1$ \\
\hline Perevalnoye & 600 & 50 & $2: 1: 1$ \\
\hline Hinganskoye & 550 & $50-70$ & $3: 1: 1$ \\
\hline Antei & 700 & $50-100$ & $2.5: 1.4: 1$ \\
\hline Darasunskoye & 700 & 27 & $1.7: 1.3: 1$ \\
\hline Irokindinskoye & 200 & 11 & \\
\hline
\end{tabular}

\section{Methods of research and principles of complex interpretation of data}

In $[8,9]$, the authors outlined the rationale for the principles of complex interpretation of geophysical fields by various methods. The basis of the applied approach is the assertion that the natural SSS of various depth levels of the Earth's crust is reflected in regional physical fields, and its upper part - in the morphological structures of the daytime relief and other neotectonic elements. The method is approved on materials on the Amur tectonic plate.

To clarify the neotectonic structure of the upper part of the crustal section in the region under investigation, the authors used various methods of interpreting satellite geodetic data $[10,11]$, results of an instrumental assessment of the stress-strain state of rock massifs of bump-hazardous ore deposits, generalizing geological, geophysical and neotectonic materials on the region. Processing and subsequent visualization of satellite images were carried out using the original programs and software environment ArcGis 9.3. The construction and direct visual study of computer volumetric 3D models of relief was carried out using GTOPO_30 altitude matrices, using Google Earth online service and original programs. The construction of a more detailed neotectonic scheme of the DalnegorskKavalerovo ore region and its surroundings was based on the morphostructural analysis of the relief and the concept of horizontal motion of tectonic flows [12]. Initial materials were digital relief models (DRM). They are interpreted using the altitude matrices srtm30 and srtm03 with visualization in the form of maps with tinted washing in color, black and white and in the form of anaglyphic images. Refinement of modern deep features of the territory was carried out according to satellite gravimetry (GRACE project).

Full-scale geomechanical studies included: instrumental measurements of parameters of properties and states of rock massifs, their seismoacoustic control and visual observations of the manifestations of rock pressure.

\section{Results}

Data on the stress state of deep horizons of the Earth's crust were obtained from the interpretation of the materials of the GRACE mission. It is established that the most bursthazardous deposits of the region (Yuzhnoye and Nikolaevskoe) are located between regional anomalies of compression and stretching. Vostok- 2 deposit is located in the contour of the regional positive anomaly. The fundamentally different geodynamic position of the studied deposits with respect to regions with unequal intensity of the present compression of the upper part of the Earth's crust (local linear anomalies of intense 
compression, associated with activated fault structures) was described by the authors in [9, 13].

On the example of Dalnegorsky ore region, a large-scale neotectonic scheme was constructed (Fig. 1). It is based on the interpretation of the morphostructural analysis of space materials (the srtm03 altitude matrix), performed within the framework of the concept of horizontal motion of tectonic flows [12]. When studying the modern structure of the upper part of the Earth's crust of Sikhote-Alin and surrounding territories, an important contribution of fold-thrust dislocations is noted [7, 14, 15, etc.]. This is also evidenced by the high values of the main horizontal stresses at all the investigated deposits (see Table 1), as well as the data of GPS measurements [16].

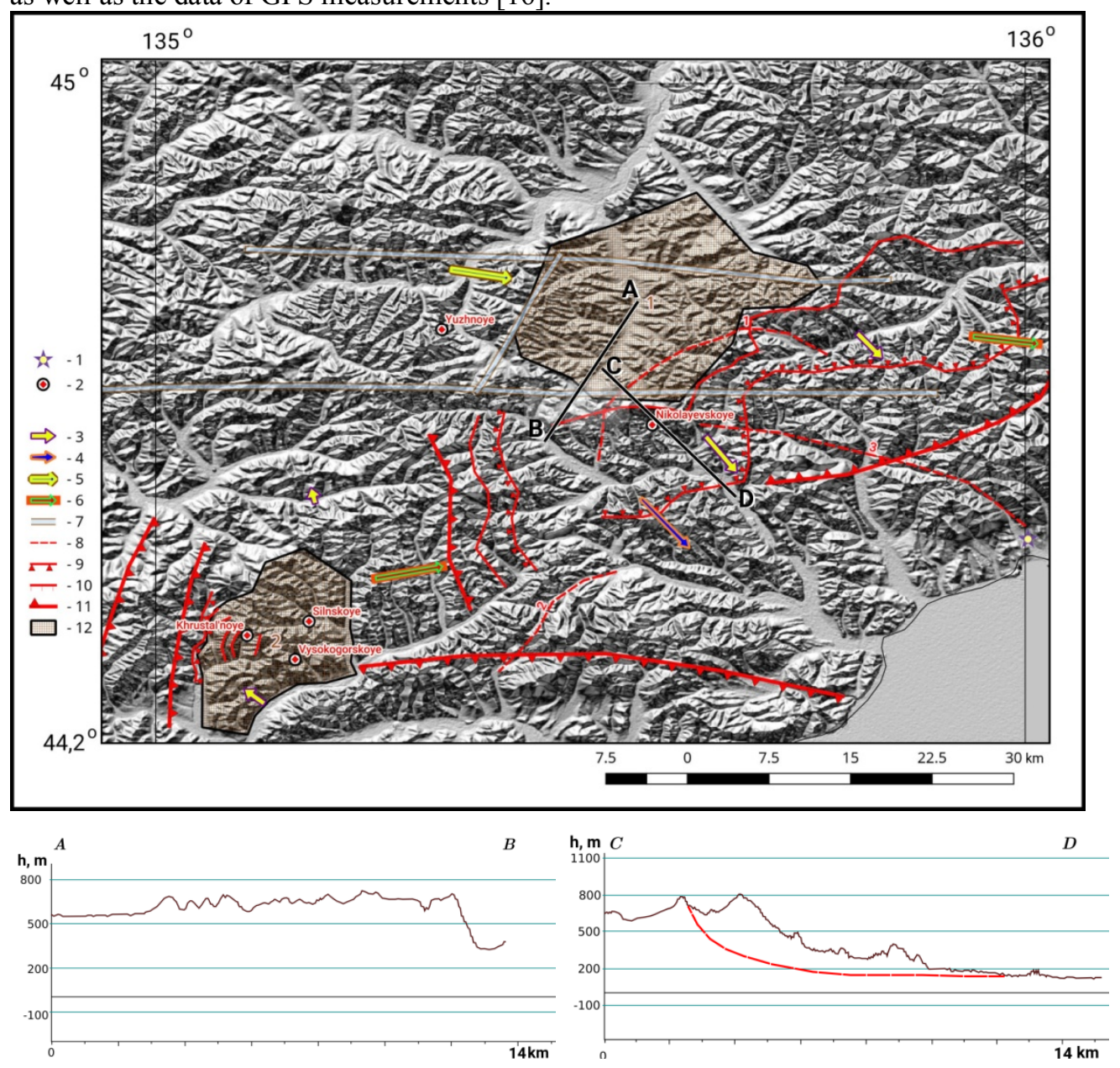

1 - earthquake in the area of Kamenka community in 2016; 2 - deposits; 3 - displacements of tectonic scales relative to each other; 4 - directions of the movement of tectonic flow of the early stages; 5 vector of modern stresses; 6 - modern directions of the movement of tectonic flow; 7 - linear stress zones; 8 - tectonic disturbances (without separation); 9 - contours of the rear borders of the covers; 10 - lines of detachment of covers from the underlying layers; 11 - thrusts; 12 - tectonic blocks (1 Verkhnenikolaevsky, 2 - Silinsky); AB and CD - the position of the relief surface profiles. The red line shows the projection of tectonic disturbance No. 1 on the vertical plane.

Fig. 1. The main structures of Kavalerovo-Dalnegorsk ore cluster, identified by DEM based on the SRTM03 altitude matrix 
The morphostructural scheme of Kavalerovo-Dalnegorsk ore region (see Figure 1) reflects features of the tectonic cover of this territory, which manifest themselves as areas of congestion and tearing of tectonic scales and blocks formed as a result of uneven horizontal displacements. With its help, it was possible to establish a clear connection (according to the latest arc fault) between Nikolaevskoe deposit and the epicenter of the earthquake located $30 \mathrm{~km}$ south-eastwards with a magnitude of 4 points on March 25, 2016, which played the role of a trigger and coincided with a strong destructive geodynamic phenomenon on deep horizons of Nikolaevsky mine [13].

It follows from the scheme that the most burst-hazardous Nikolaevskoe and Yuzhnoye deposits are located in the peripheral zone of the Verkhnenikolaevsky hard block of the upper part of the Earth's crust. The block is clearly distinguished by the features of the morphology of the relief and is composed of early Cretaceous terrigenous-sedimentary deposits, and is also expressed by a positive anomaly of the gravitational field. However, on this the generality of the neotectonic position of the named objects ends. Thus, Nikolaevskoe deposit is located in the zone of transition from a rigid block to an active tectonic structure of the type of reversed overthrust. In this area, a tear-off zone (structure 1 in Figure 1 and CD section), which affects the instability of the entire system, was outlined in the rigid block. If this field is confined to the rear zone of tearing of smaller tectonic blocks (scales), then the Yuzhnoye deposit is to the areas where they are clustering. The dragging effect is expressed particularly clearly at the eastern edge of a large limestone plate (olistolith), held by Nikolaevskoe deposit (Fig. 2).

Other deposits of the Kavalerovo ore region (see Figure 1) are localized within the Silin neotectonic block, which is characterized by the predominant tearing of tectonic scales and lower average relief heights in comparison with neighboring areas. The level of tectonic stress within this block is predicted to be lower than in the neighboring block, which is confirmed by the absence of signs of burst hazard during underground mining.

Analysis of the geomechanical situation at Nikolaevsky deposit showed that in recent years the movement of the mining front towards the eastern edge of the olistolite has led to an increase in the number and intensity of the dynamic manifestations of rock pressure. Their most part is confined to the geodynamically active section of the rock massif, within which there is structural reorganization with the opening of tectonic disturbances and movements along the boundaries of tectonic blocks [13]. Widely manifested at Nikolaevsky and Yuzhny mines has been mine seismicity, which is a reaction of the natural geoenvironment to anthropogenic activity [3-5]. Anthropogenic impact in conditions of high tectonic disturbance of the rock massif can lead to the spontaneous occurrence of foci of trigger seismicity with unpredictable energy [3]. At Nikolayevskoye deposit, the centers of mine seismicity are mainly confined to the ribbed zones of a large plate of ore-bearing limestones (especially its eastern part), where shocks and shifts of smaller blocks occur during the process of rebuilding the rock massif.

\section{Conclusions}

A comprehensive analysis of geological, geophysical and geomechanical data with the use of materials from the remote study of the Earth from space (GRACE mission data for the calculation of stress fields and radar images of the Earth's surface) made it possible to significantly refine the kinematics of the process of modern deformation of the upper part of the Earth's crust within the boundaries of the Edge-Asian model region . It is established that the peculiarity of the region is the significant contribution of the natural component to the total current SSS of rock massifs of impact-threatening deposits.

The fundamentally different position of the deposits of the Kavalerovo-Dalnegorsk ore region (located in the continent-ocean transition zone) has been revealed in relation to the 
tectonic structures that are unevenly activated in the upper part of the section during the current stage of development of the area and are formed as a result of uneven horizontal displacements.

The interdependence of the geodynamic position of deposits with the level of stresses in rock massifs is established, which must be taken into account when designing and conducting mining operations in severe mining-geological and burst-hazard conditions.

This research was supported by Russian Science Foundation grant No.16-17-00018.

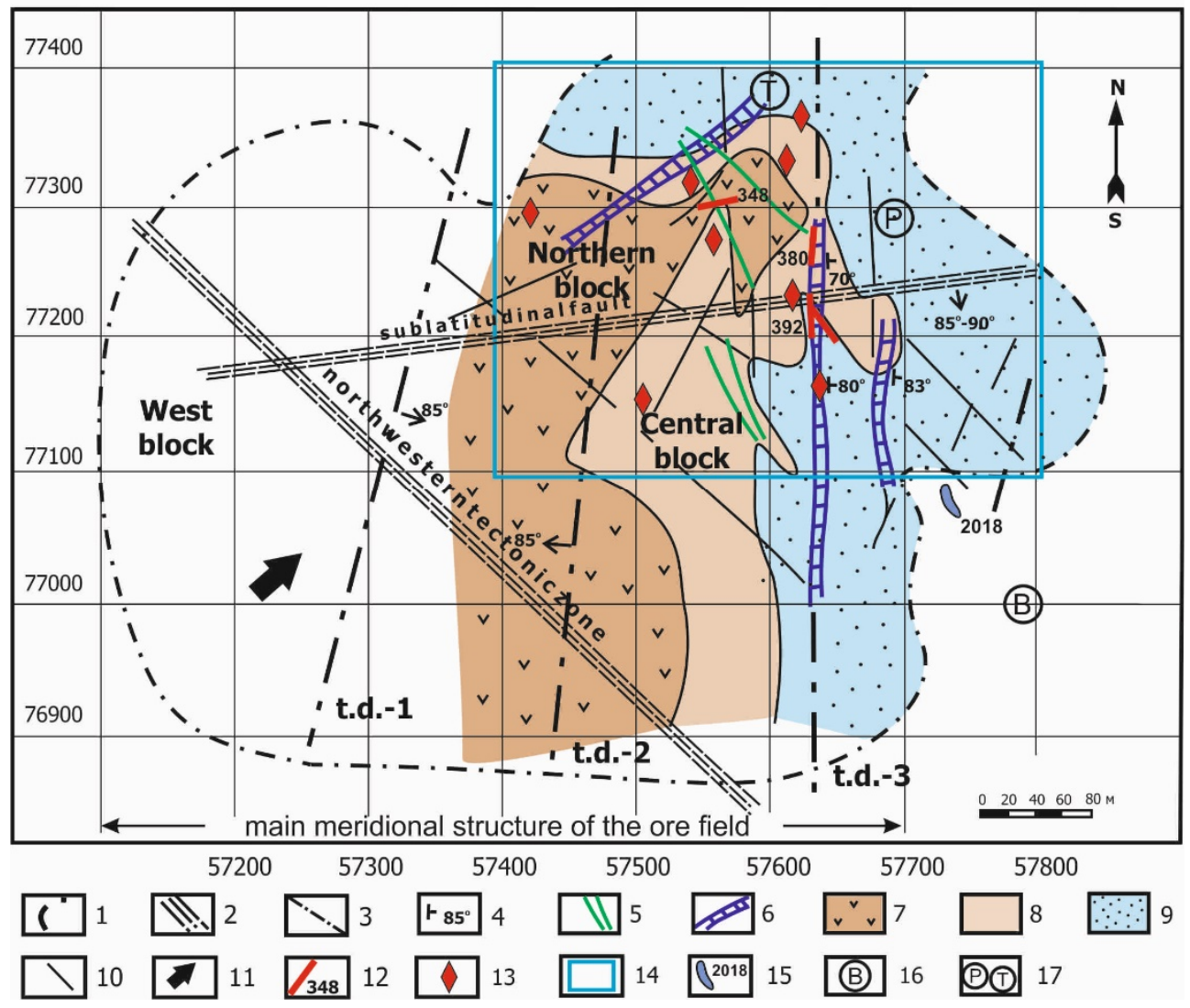

1 - projection of the outline of the olistolite on the horizontal plane; 2-6 - geological exploration data: 2 - block-forming faults and their names; 3 - other tectonic disturbances and their numbers; 4 established elements of occurrence; 5 - dikes of medium and basic composition; 6 - gorges in the body of limestones, filled with metasomatites; 7-10 - geodynamic regions formed by the morphological features of the olistolith and the modern stress field: 7 - relatively geodynamically stable (raised or prihrebtovy) area; 8 - a hollow-slope region with intermediate geodynamic activity; 9 - steeply oblong geodynamically active peripheral region; 10 - lineaments of the topography of the roof of the olistolite; 11 - direction of the modern horizontal movement of the ore-bearing geoblock and the main horizontal compression of the rock massif; 12 - location of uncovered cracks associated with dynamic manifestations on 03.24.2016; 13 - position of large dynamic manifestations of rock pressure in 2016-2017; 14 - general contour of geoacoustic monitoring studies, 15 - new steeply falling zone of anomalous acoustic activity (2018) near the eastern edge of the olistolith (horizons 340 - minus $400 \mathrm{~m}$ ); 16 - location of the mass explosion (2017); 17 - places of manifestation of dynamic events caused by the explosion in 2017.

Fig. 2. Block structure and geodynamic zoning of limestone body of Nikolaevsky deposit 


\section{References}

1. I. Iu. Rasskazov, Monitoring and management of rock pressure on mines of Far Eastern region. - Moscow: Mining book. p. 329. (2008)

2. $\quad$ Butra, J., Kudeiko, J. Cuprum. 61 (4). P. 5-20. 17. (2011)

3. V.V. Adushkin, S.B. Turuntayev, Technogenic seismicity - induced and triggered. - Moscow: IDG RAS, 2015.

4. Li, T., Cai, M. F., Cai, M. International Journal of Rock Mechanics and Mining Sciences. 44 (8). pp. 1149-1171. 2007

5. $\quad$ Marcak, Henryk, Mutke, Grzegorz. J. Seismol. 17 (4). 1139-1148. (2013)

6. Paige E. Snelling, Laurent Godin, Stephen D. McKinnon. International Journal of Rock Mechanics and Mining Sciences. 58. 166-179. (2013)

7. Geodynamics, magmatism and metallogeny of the East of Russia. Vladivostok: Dalnauka. p. 572. (2006)

8. Present Day Stress Strain State in the Upper Crust of the Amurian Lithosphere Plate / I.Iu. Rasskazov, B.G. Saksin, V.A. Petrov, B.F. Shevchenko, V.I. Usikov, G.Z. Gilmanova // Izvestia, Physics of the Solid Earth. 50 (3). 444-452. (2014)

9. B.G. Saksin, I.Iu. Rasskazov, B.F. Shevchenko. Physico-technical problems of mining. 2. 53-65. (2015)

10. B.F. Shevchenko, B.G. Saksin, G.Z. Gilmanova, M.M. Dovbnich. GIAB: Far East. OB4. 49-60. (2013)

11. O.V. Rybas, G.Z. Gilmanova, The exploration of the Earth from Space. 6. 4552. (2011)

12. V.I. Usikov. Pacific Geology. 6. 14-33. (2011)

13. I.Iu. Rasskazov, B.G. Saksin, V.I. Usikov, M.I. Potapchuk. Mining magazine. 12. 13-19. (2016)

14. V.P. Nechaev. Pacific Geology. 6. 91-101. (2015)

15. V.Iu. Zabrodin, O.V. Rybas, G.Z. Gilmanova, The fault tectonics of the mainland part of Russian Far East. - Vladivostok: Dalnauka. pp. 132. (2015)

16. V.G. Bykov, V.A. Bormotov, A.A. Kokovkin et al. Bulletin of Far Eastern Division of Russian Academy of Sciences. 4. 83-93. (2009) 